\title{
UN DOCUMENTO ACERCA DE ANDRES ISLAS
}

Pintor mediocre que florece entre 1753 y 1773 . Las obras de que tenemos noticia, única información que podemos consignar acerca de su persona; por lo que el documento que reproducimos resulta de interés, son las siguientes:

Dos retratos del obispo Palafox en la bodega de ta capilla de Guadahupe, de la Catedral de México.

Retrato de don José Escandón, existente en la capilla de Guadalupe del Seminario de Querétaro. Futé reproducido en el tomo XIV de las publicaciones del Archivo General de la Nación.

- Retratos de Carlos III, el Virrey Bucareli y el Primer Conde de Regla, en la Dirección del Monte de Piedad. Los tres costaron cien pesos.

Retrato de Clemente XIV en el Mureo Nacional, firmado en 1769.

Retrato de la Marquesa del Jaral de Berrio, firmado en 1753. Lo vi en poder de un particular.

Genaro Estrada menciona un retrato de Sor Juana Inés de la Cruz, firmado en México en 1772, existente en el Museo Provincial de Toledo.

Couto dice (pág. 86) : "Andrés Islas pintó en 1773 el retablo de San Juan Evangelista, que está en la capilla de Aranzazu, y algo que hay en la Profesa; todo de menos que mediano mérito".

Villa (pág. I.), añade: "De este autor sólo conozco un lienzo de tres varas en cuadro, que en medio de un adorno arquitectónico del estilo plateresco, colocó una Sagrada Fatuilia presidida por el Eterno Padre... Está fechado en $1770^{\prime}$.

M. T.

Digo yo dn. Andres de Yslas Maestro pintor vecino de esta ciudad, que he recivido de dn. Juan Antonio de Yermo actual Tesorero de la 
Ytte. Cofradia de Ntra Sera de Aranzazu, la cantidad de dos mil quatrocientos cincuenta y siete pesos por la obra que le he entregado para adorno de la Capilla de dha Ytte. Cofradia, y es en esta forma: vn mil trescientos cincuenta pesos de diez y ocho Estatuas de barios Santos para los coraterales nuebos de Aranzazu, Vegoña, y Guadalupe, acabadas del todo, a rrazon de setenta y cinco pesos cada una; quinientos pesos de v11 corateral de Prespectiva en la Puerta del costado que llega hasta la Cortniza, su Patrono Sn. Juan Evangelista, con Marco dorado, repisa, candeleros y Atriles: Setenta pesos de vn lienzo a medio punto que cierra tho corateral de Prespectiva, y en que está pintado el templo de Sn. Juan de Letran con los Santos Patriarcas Domingo y Franc $^{\circ}$ como reparadores de la Yglesia: treinta y seis pesos de vn lienzo de Ntra Sera de Guadalupe de dos baras y media de largo, que es el principal de vn corateral: noventa y seis ps. de quatro lienzos de la Aparicion de Ntra Sera de Guadaltupe para su corateral: Ciento y sesenta pesos de ocho lienzos de la vida de Ntro Señor y Ntra Señora, en que se incluyen dos de $\mathrm{St}^{\circ}$. Domingo de Silos, y Sn. Bernardo, qe. estan colocados en los coraterales de Vegoña, y Guadalupe á razon de veinte ps. cada uno: $\mathrm{Y}$ doscientos quarenta y cinco ps. de los quatro lienzos que cierran desde las cornizas de los Coraterales de Vegoña y Guadalupe hasta las bodegas en qe, estan pintados la coronacion de la señora, y la Concepcion Guadalupana, la Aparicion de Ntra Sera de el Pilar a Sn.tiago aPostol, y santa Rosa Maria de Lima con Ntra Señora.. Y para que conste el estar satisfecho doy este en Mexico, a cinco dias de el mes de Julio de mil setecientos setenta y quatro ạños.

Andrés de Yslas, rúbrica. 